\title{
AN ANALYSIS OF CROSS-SHORE PROFILE EVOLUTION OF A SAND AND A COMPOSITE SAND-GRAVEL BEACHES
}

\author{
Harshinie Karunarathna ${ }^{1}$, Jose Horrillo-Caraballo ${ }^{1}$, Roshanka Ranasinghe ${ }^{2}$, Andrew Short $^{3}$ \\ and Dominic Reeve ${ }^{1}$
}

\begin{abstract}
In this paper, cross-shore morphodynamic evolution of a sand and sand-gravel composite beach, are compared and contrasted used historic surveys of beach profiles. The differential behavior of cross-shore morphodynamics at a range of time scales covering event-scale dynamics up to intra-annual scale variability are investigated and discussed. The application of equilibrium concept to both beach types is explored through Dean's equilibrium profile and Vellinga's beach erosion profile. Variability of cross-shore profile dynamics are quantified and discussed through bulk statistical analysis. Multi-scale morphodynamic trends are determined using Empirical Orthogonal Eigenfunction (EOF) analysis. The above analysis enables to recognise failure mechanism of each beach type during a storm.
\end{abstract}

Keywords: composite sand-gravel beaches, cross-shore beach morphodynamics, beach profiles, Milford-on-Sea Beach, Narrabeen Beach

\section{INTRODUCTION}

Morphological evolution of a beach is characterised by cross-shore and long-shore morphodynamic changes. Long-shore coastal evolution is mainly characterised by varying coastal forms such as changing shoreline position, beach rotation and development of rhythmic features. Cross-shore beach change is associated with changes to the shape of cross-shore profile in time and space. Our focus here is the morphodynamic changes in the cross-shore direction. Changes in crossshore beach profiles are controlled by many factors including waves, tidal flows and sediment characteristics. However, these changes can also depend on the beach type.

Composite sand-gravel beaches form many parts of coastal systems in the UK and around the world. They are composed of a gravel inter- to supra-tidal swash zone and sand lower to sub-tidal surf zone. The importance of such beaches as a part of natural coastal systems and as a form of coastal defence is well recognised in the literature (Carr, 1983; Bradbury and Powell, 1992). There are a growing number of reports and studies of their degradation, and in some instances severe cutback (e.g. Chadwick et al., 2005) and breaching (Carter and Orford, 1993).

It has been reported that the cross-shore variability of composite sand-gravel beaches is distinctly different to that of sand beaches (Larson and Kraus, 1994; Pontee et al., 2004). It is also different to the other forms of coarse-grain beaches (mixed beaches and pure gravel beaches) in terms of profile shape, profile response to hydrodynamic forcing, sediment characteristics and sediment distribution (Pontee et al., 2004). The composition and cross-shore distribution of beach sediment plays a major role in determining the morphodynamic response of a beach profile to environmental forcing (Pontee et al., 2004). Sand beaches have gentler cross-shore slopes and wide but shallow surf and swash zones while composite sand-gravel beaches in contrast have coarse steep swash zone that changes abruptly into a low gradient sandy lower inter-tidal to sub-tidal zone (Carter and Orford, 1993). Gravel has a tendency for net onshore transport due to the more energetic wave uprush followed by less energetic back-wash (Carter and Orford, 1984; Carr, 1983). As a result, sediment sorting takes place across the profile where gravel accumulates at the supra-tidal and upper inter-tidal region of the profile while sand accumulates at the lower inter-tidal and sub-tidal regions thus forming composite beaches (McLean and Kirk, 1969). Due to the presence of a steep gravel upper shoreface and a gentler sand lower beach, composite beaches show characteristics of both reflective and dissipative beaches at different times of a tidal cycle.

Beach morphodynamic change in the cross-shore direction takes place at a range of time scales: millennial scale evolution as a result of Quaternary sea level changes; long term variability in the time scales of several decades to a century associated with climate change impacts; medium-term evolution in the time scales of several years to a decade, associated with engineering intervention and prevailing sedimentary processes; and short term variability in the time scales of days to a year as a result of weather conditions (storms) and seasonal changes.

Early studies of Bruun $(1954)$ and Dean $(1971,1977)$ developed the concept of equilibrium beach profiles and empirical functions to describe the equilibrium profile shape. Swart (1974) and Sunamura

\footnotetext{
${ }^{1}$ College of Engineering, Swansea University, Singleton Park, Swansea SA2 8PP, UK

${ }^{2}$ Department of Water Engineering, UNESCO-IHE, PO BOX3015, 2601 DA Delft, The Netherlands.

${ }^{3}$ School of Geosciences, University of Sydney, NSW2006, Australia.
} 
and Horikawa (1974) examined characteristics of beach profiles through laboratory investigations and identified erosive and accretive profiles, relating profile geometry to incident wave conditions and sediment characteristics. Vellinga $(1983,1984)$ developed a relationship between cross-shore distance and profile depth for erosive beach profiles, which was a function of grain size. There were several attempts to understand cross-shore morphodynamic variability of beaches through statistical analysis of waves and beach profiles (Larson and Kraus, 1994).

Even though the understanding of beach morphodynamic evolution is essential for both developing predictive models and effective beach management, research on coarse grain beaches is scarce, with existing studies either limited to geological time scales (Kirk, 1980; Carter and Orford, 1984; Carter, 1986) or short-term scales (Jennings and Shulmeister, 2002; Pontee et al., 2004; Ivamy and Kench, 2006; Masselink et al. 2010; Alegria-Arzaburu et al., 2010). Besides, these studies were done on either pure gravel or mixed sand-gravel beaches. Composite sand-gravel beaches differ significantly from pure gravel or mixed sand-gravel beaches where sand and gravel are spatially separated in their cross-shore profile (Pontee et al., 2004). Morphodynamic variability of composite sand-gravel beaches at a full range of time scales is not well understood.

The focus of this study is to contribute to fill this gap by analyzing the cross-shore behavior of sand-gravel composite beaches and compare and contrast that with the behavior of a sandy beach. For this purpose, historic beach profile measurements of Milford-on-Sea beach, UK will be used and compared that with similar data from Sandy Narrabeen Beach in NSW, Australia.

\section{FIELD SITES}

\section{Milford-on-Sea Beach}

Milford-on-Sea is a composite sand-gravel beach that forms a part of the Christchurch Bay beach system in the UK. The beach extends about $3 \mathrm{~km}$ to the west from the Hurst Castle Spit (Figure 1). It is narrow and steep at the western side and has a landward margin of receding cliffs, which becomes wide and less steep at the eastern end.

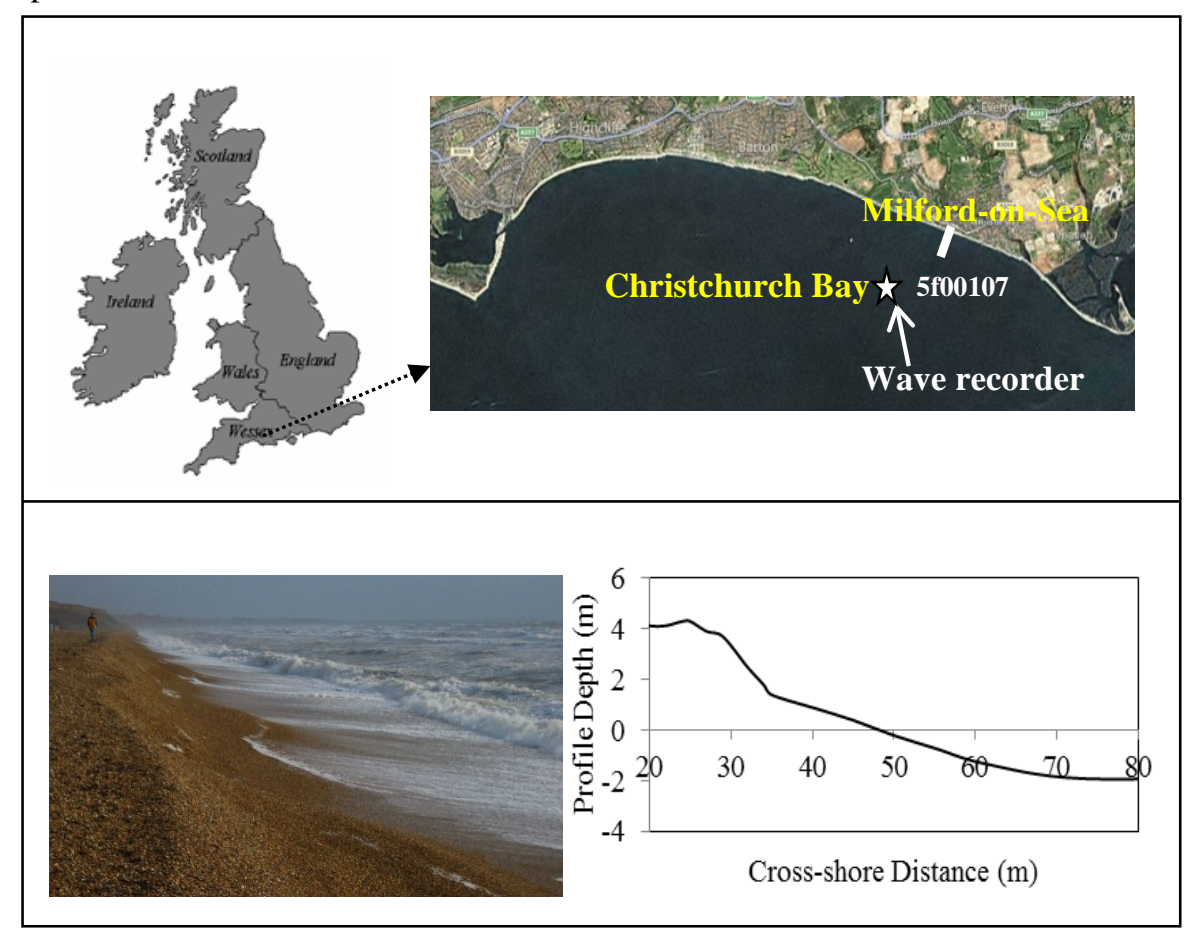

Figure 1. Milford-on-Sea Beach, it's location in the UK and the time mean profile at transect 5 f00107.

The Milford-on-Sea beach has a steep upper beach face with a gradient between 1:5 and 1:7 and a moderate inter-tidal beach with a gradient between 1:10 and 1:20. The gentler sub-tidal beach is characterised by highly mobile and segmented multiple alongshore bars. Cross-shore gradients of the western part of Milford-on-Sea beach are significantly steeper than those on the eastern part. The 
sediment grain size at Milford-on-Sea beach significantly varies along the cross shore profile. Coarse shingles and pebbles with a median grain diameter $\left(D_{50}\right)$ around $16 \mathrm{~mm}$ dominate the upper beach. A sand-gravel mix which has $D_{50}$-gravel $=10 \mathrm{~mm}$ and $D_{50}$-sand $=1 \mathrm{~mm}$ with only $62 \%$ sand fraction, dominates the upper inter-tidal areas (Martin-Grandes et al., 2009). No quantitative measurement on sediment sizes at the lower inter-tidal area is available but visual inspection shows sediment is predominantly sand. Sediment grain sizes on the western end of the beach are slightly coarser than those on the eastern end, which contributes to the alongshore variation of the beach slope. Small scale beach nourishment had been taken place between 1996 and 1999, to stabilise the beach.

Christchurch Bay receives semi-diurnal tides with a moderate mean spring tidal range of $2.0 \mathrm{~m}$ $\mathrm{OD}$, reducing to $0.8 \mathrm{~m}$ OD during neap tidal cycle. Mean high water spring (MHWS), mean low water spring (MLWS) and Mean water level (MWL) are $0.87 \mathrm{~m},-1.13 \mathrm{~m}$ and $0.14 \mathrm{~m}$ above OD respectively. Tidal currents, as high as $3.0 \mathrm{~m} / \mathrm{s}$, are observed in close proximity to the Milford-on-Sea beach (SCOPAC, 2003). Waves are incident predominantly from the SSW direction with occasional SSE waves. Waves at the eastern end of Christchurch Bay are more energetic than those approaching the western end due to the sheltering effect of Hengistbury Head. According to SCOPAC (2003), typical (1-year return period) and extreme (1 in 100 year) significant wave heights at Milford-on-Sea, as $2.5 \mathrm{~m}$ and $3.4 \mathrm{~m}$ respectively.

Milford-on-Sea beach is subjected to typical winter-summer wave conditions approaching from the English Channel. As a result, beach variability during winter months is considerably higher than that during the summer months where a few metres of beach lowering takes place. Overall morphodynamics of the Milford-on-Sea beach is determined by its swash dominance.

Beach profiles have been surveyed at 45 cross-shore beach transects along Christchurch Bay. Surveys at cross-shore beach transect 5f00107, (See Figure 1), where net long-shore transport is minimal (SCOPAC, 2003), were selected for the analysis here. There are 49 profile surveys in total, measured between 1987 and 2005, are available at this transect with an average of 3 surveys per year. The length of profile measured varied from survey to survey, but always went out at least to MLWS. Thus, all profiles were truncated at MLWS to provide a consistent basis for analysis. The shoreline position is defined as the point of intersection between the cross-shore profile and the Mean Water Level (MWL).

\section{Narrabeen Beach}

Narrabeen is a wave-dominated embayed beach located $20 \mathrm{~km}$ north of Sydney, in NSW, Australia (Short and Wright, 1981). The beach that faces east into the Tasman Sea, is $3.6 \mathrm{~km}$ long and bounded by two headlands, Narrabeen Head to the north and Long Reef Point to the south (Figure 2). It is composed of medium to fine quartz and carbonate sands with $D_{50}=0.3-0.4 \mathrm{~mm}$ and has a relatively steep upper beach and a gentler lower beach in the sub-tidal region.

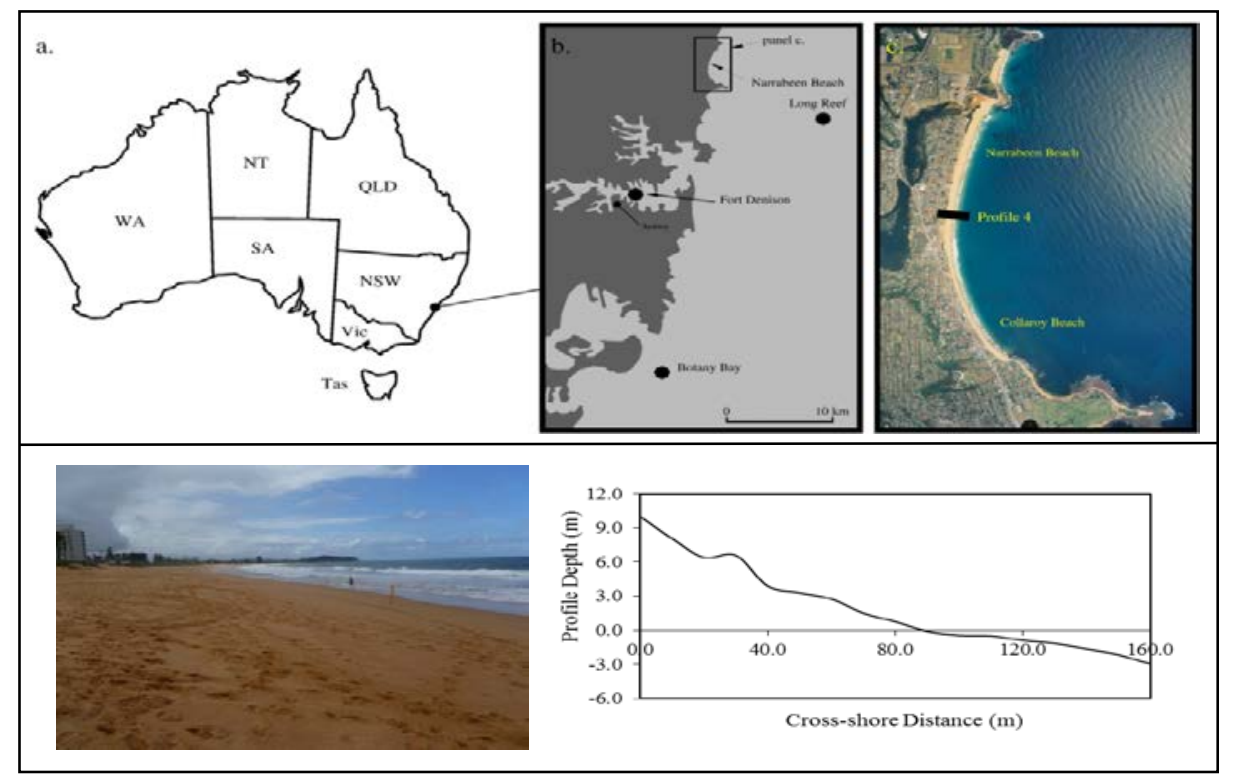

Figure 2. Narrabeen Beach, it's location in the UK and the time mean profile at Profile 4. 
Beach profiles at five cross-shore locations along the Narrabeen Beach were regularly measured first at bi-weekly intervals and then, at monthly intervals since 1976, by the Coastal Studies Unit, University of Sydney. Surveys were undertaken at low tide and profiles were recorded at $10 \mathrm{~m}$ crossshore intervals from a fixed bench mark at the landward limit of the active beach at $10 \mathrm{~m}$ elevation. Hourly non-directional (1976-1992) and directional (1992-2005) wave data were also measured at an offshore wave buoy located at the Long Reef Point, at a depth of $80 \mathrm{~m}$. Cross-shore beach profile surveys carried out at Profile 4 (Figure 2), which is situated in the central part of the Narrabeen Beach, is used for the analysis presented herein. Profile 4 was selected for this analysis as it is the least likely location to be affected by the cyclic beach rotation phenomenon that operates at Narrabeen beach (Short and Trembanis, 2004; Ranasinghe et al., 2004a).

Narrabeen Beach is exposed to highly variable, moderate- to high-energy wind waves superimposed on long period, moderate- to high-energy south-easterly swell waves (Short and Wright, 1981). Waves are derived from three cyclonic sources: Mid-latitude cyclones pass across the southern Tasman Sea all-year-round, generating south-easterly swell; extra-tropical cyclones off NSW coast generating east and south-easterly waves peaking between May and August; tropical cyclones that generate moderate to high north-easterly and easterly swell during February and March. In addition summer (December to March) sea breeze generating low to moderate north-easterly seas. 20\% of the waves are found to exceed $2 \mathrm{~m}$. Mean significant wave height and peak period in the study area are 1.6 $\mathrm{m}$ and $10 \mathrm{sec}$ respectively (Short and Wright, 1981; Short and Trenamon, 1992). On average, Narrabeen Beach, is subjected 12 storms per year (based on the local definition that $H_{\mathrm{s}}>3 \mathrm{~m}$ lasting more than $1 \mathrm{hr}$ represents a storm. The beach experiences micro-tidal, semi-diurnal tides with mean spring tidal range of $1.6 \mathrm{~m}$ and neap tidal range of $1.2 \mathrm{~m}$. MHWS and MLWS are $0.9 \mathrm{~m}$ and $-0.7 \mathrm{~m}$ above Australian Height Datum (AHD) respectively. The effect of tides on the morphology of the Narrabeen Beach is considerably less than waves (Short, 1985; Short and Trembanis, 2004).

Due to the prevalence of moderate to high wave energy conditions and the exposed nature of the beach, the morphodynamic response of Narrabeen Beach is highly variable and extremely rapid where erosion and accretion can take place any time of the year. Accordingly, cross-shore beach profile shape varies rapidly with time, (Wright and Short, 1984; Ranasinghe et al., 2004b).

\section{CROSS-SHORE BEACH PROFILE ANALYSIS}

In order to analyse and quantify cross-shore beach profile evolution of composite sand-gravel beach at Milford-on-Sea and compare that with the sandy Narrabeen Beach, three different analysis methods are used: Bulk statistical analysis, Equilibrium profile analysis and Empirical Orthogonal function (EOF) analysis. These three methods collectively provide insights into profile variability at different time scales.

\section{Bulk Statistical Analysis}

Bulk statistical analysis provides information on the mean beach profile and profile variability around the mean. Figure 3 shows mean cross-shore profile, the profile envelope and the standard deviation of the profile depth at Profile $5 f 00107$ of Milford-on-Sea Beach. The mean profile is indicative of a steep upper beach with a gradient of 1:5 and an inter-tidal beach with gradient 1:10. The mean beach width at the mean shoreline (MSL), measured from the shoreward limit of the active profile at the benchmark, is $43 \mathrm{~m}$. The envelope of the beach profiles shows that the beach width at the shoreline varies by around $13 \mathrm{~m}$ during the 18 year study period, with a minimum width of $37 \mathrm{~m}$ and a maximum of $50 \mathrm{~m}$. The maximum cross-shore beach movement of $17 \mathrm{~m}$ occurs around 2-3 m elevation. The envelope shows the upper beach berm development/recession associated with accretion/erosion in the swash region, which is typical of coarse-grain beaches. However, it should be noted that these results may have been slightly affected by the beach filling that had been carried out at Milford-on-Sea between 1996 and 1999 (SCOPAC, 2003). The standard deviation peaks in the supratidal zone, around $2 \mathrm{~m}$ elevation above mean water level. This is well above the inter-tidal zone and that indicates the swash dominance in cross-shore beach morphodynamics of a composite sand-gravel beach. A secondary peak is seen at $-1 \mathrm{~m}$ water depth, which is the swash region at low tide. Even though the standard deviation sharply drops through the inter-tidal zone, values well above zero at the MLWS indicate that the active beach profile extends further seaward. 

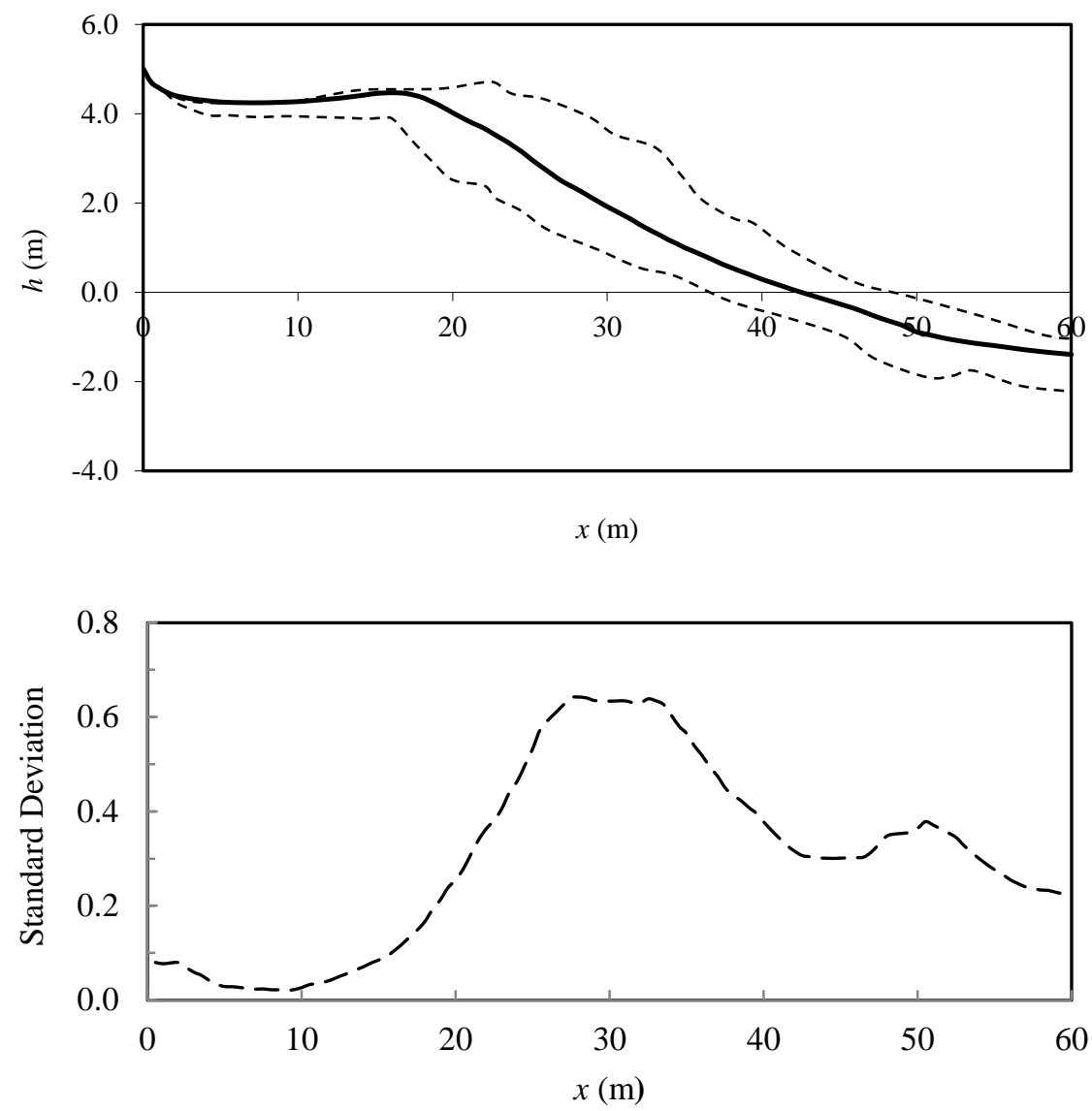

Figure 3. Time-averaged beach profile, profile envelope (top) and standard deviation of profile depth (bottom) at transect 5f000107, Milford-on-Sea Beach.

At Milford-on-Sea, the highest beach variability occurred at the supra-tidal level (2-3m MSL). This is attributed to strong swash movements associated with incident wave groupiness and waves breaking on or at close proximity to the shoreline (Karunarathna et al., 2005; Masselink et al., 2010). The surf similarity parameter at Milford-on-Sea calculated on the mean inter-tidal profile gradient with mean wave steepness is 1.4 , showing plunging to surging waves near the waterline. Highly dynamic swash motions enabled by plunging/surging waves then initiate the strongest sediment transport at the upper beach face.

In Figure 4, mean cross-shore profile with profile envelope and standard deviation at Narrabeen Beach profile 4 are shown. The width of the mean profile at the shoreline (MWL) with respect to the selected bench mark at the top of the dune is $100 \mathrm{~m}$. The envelope of the measured profiles shows that the beach width at the shoreline fluctuates by about $70 \mathrm{~m}$ in the on- off-shore direction, which is $70 \%$ of the mean beach width. The standard deviation of beach profile depths drawn against offshore distance shows three peaks. The largest peak is around $0.8 \mathrm{~m}$ above MWL, which is at the upper region of the inter-tidal zone. A secondary peak with standard deviation is nearly half that of the primary peak, is seen around $6 \mathrm{~m}$ above mean water level, which may be attributed to variability of the upper beach as a result of frequent storms. The peak at the end of the profile indicates that the surveys do not extend to the depth of closure. 

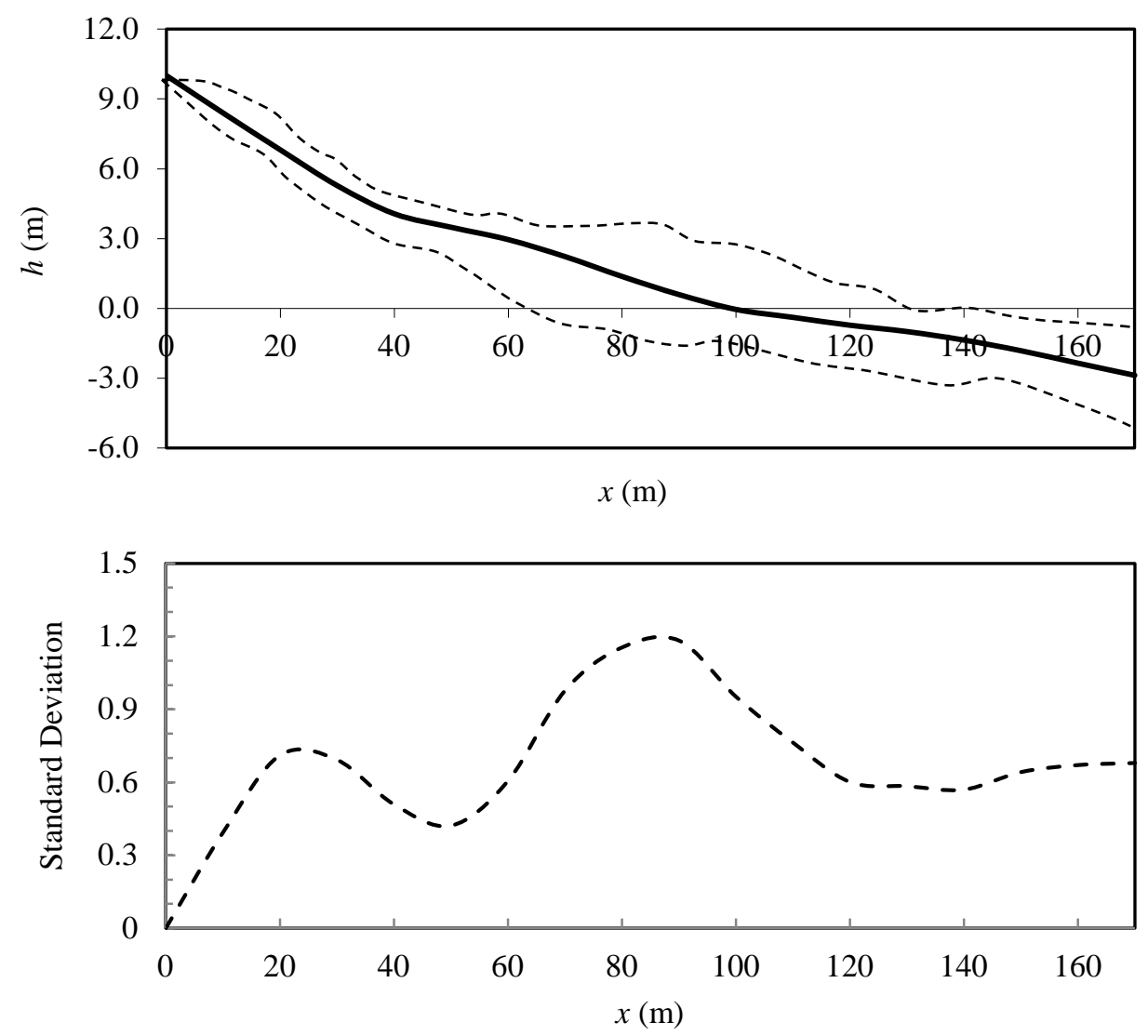

Figure 4. Time-averaged beach profile, profile envelope (top) and standard deviation of profile depth (bottom) at Profile 4, Narrabeen Beach.

At Narrabeen Beach, cross-shore variability is highest in the inter-tidal region. This can be related to the gradual wave dissipation on the gentle sub-tidal beach which results in more sediment transport in the surf zone than that in the swash zone. The surf similarity parameter determined using the average inter-tidal beach slope with mean wave steepness on the Narrabeen Beach is approximately 0.24, showing mostly spilling breakers. Swash movements on gentle beaches with spilling breakers are significantly lower than that on steep beaches due to partial or full saturation of the surf zone as a result of incident wave energy dissipation due to wave breaking (Baldock and Holmes, 1999; Karunarathna et al., 2005).

\section{Equilibrium Profiles}

Equilibrium profile shape gives the profile response to steady wave forcing. The empirical curves determined by Bruun (1954), Dean $(1977,1991)$ and Vellinga (1983) to characterize equilibrium beach profile shape, were tested and applied only to sand beaches. In this study, we compared Dean (1977) and Vellinga (1983) profiles with the mean beach profile at both Milford-on-Sea and Narrabean profiles.

At Milford-on-Sea, $D_{50}$ was taken as $10 \mathrm{~mm}$ (Martin Grandes et al., 2009). $D_{50}$ for Narrabeen Beach was taken as $0.35 \mathrm{~mm}$ (Short and Trembanis, 2004). The depth of the equilibrium profile is calculated from the mean high water level (MHWL). The beach profile shape parameter $A$ in the Dean model is determined from Moore's (1982) curve for given sediment sizes. The resulting Dean's equilibrium profiles and Vellinga's erosion profile for Milford-on Sea (profile 5f00107) and Narrabeen beach (Profile 4) are shown in Figure 5. 

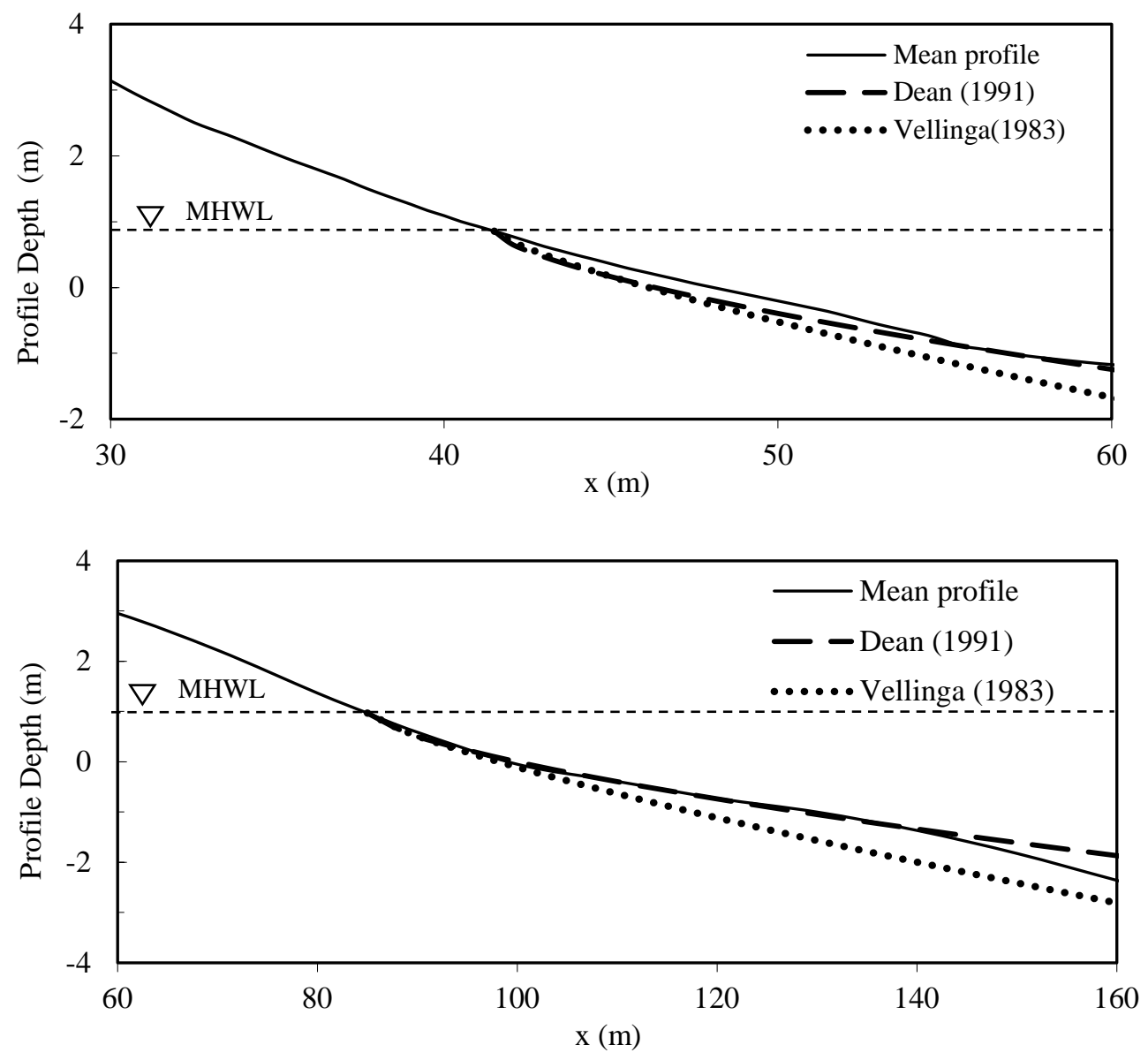

Figure 5. Comparison of time-mean beach profile with Dean (1977) equilibrium profile and Vellinga (1983) erosion profile. Milford-on-Sea (top) Narrabeen Beach (bottom).

At Narrabeen Beach, the mean profile is in good agreement with the Dean's equilibrium profile, with less than $5 \%$ root mean square error. This could be expected as Narrabeen Beach consists mostly of uniformly distributed sand and is similar in type to the beaches used to derive Dean's equilibrium profile. Vellinga's profile agrees well with the mean profile in the upper inter-tidal region but overestimates the lower inter-tidal region. This may partly be attributed to the slightly steeper frequent storm waves $\left(H_{\mathrm{s}} / L_{\mathrm{s}} \sim 0.042\right)$ prevailing at Narrabeen than the wave steepness considered for deriving Vellinga's erosion profile $\left(H_{\mathrm{s}} / L_{\mathrm{s}} \sim 0.034\right)$.

At Milford-on-Sea beach, Dean's equilibrium profile slightly overestimates the mean profile in the upper part of the inter-tidal zone and is in better agreement in the lower inter-tidal zone. This could mainly be attributed to the fact that Moore's (1982) relationship is based on a uniform grain size to determine profile scale parameter whereas the inter-tidal region of the Milford-on-Sea beach consists of sediment with a bimodal distribution with $88 \%$ gravel $12 \%$ sand. Pilkey et al. (1993) describes the difficulty in choosing a single shape parameter for beaches with large cross-shore sediment variability as well as the shortcomings of the Moore's expression for A. Overall, despite possible differences between wave energy dissipation on the steep Milford-on-Sea beach and on a gentle slope associated with Dean's profile shape parameter, the mean sub-aqueous profile shape of Milford-on-Sea beach agrees well with the concave shape of the Dean's profile shape with only $11 \%$ root mean square error. On the other hand Vellinga's profile significantly overestimates the mean profile throughout the intertidal region, which could again be attributed mainly to the bimodal sediment composition at Milfordon-Sea. This shows that the Dean's profile can be taken as a suitable measure to describe long-term averaged profile shape of a composite beach, if time averaging is taken over a sufficiently long period of time. However, the overall profile shape of a composite sand-gravel beach cannot not be simply determined by wave dissipation and a single sediment size where profile response to wave action is complicated by the complex mix of sediment and sediment sorting across the profile. 


\section{Empirical Orthogonal Eigenfunction (EOF) Analysis}

EOF analysis is widely used to investigate patterns in beach variations (e.g. Winant et al.,1975 and Wijnberg and Terwindt, 1995) and other coastal features (e.g. Reeve et al., 2001; Kroon et al., 2008; Reeve et al 2008). The method maps the observed coastal morphological data into a set of shape functions known as eigenfunctions that are determined from the data itself. When applied to crossshore beach profiles, it can reveal patterns of variation about the mean profile shape, such as bars and toughs (Pruszak, 1993; Larson et al., 2003; Kroon et al., 2008).

EOF analysis was performed on the beach profiles measured at both study sites. The first five normalised spatial eigenfunctions for Profile 5f00107 at Milford-on-Sea and Profile 4 at Narrabeen Beach are shown in Figure 6. The dark line in the figures gives the first eigenfunction that corresponds to the mean cross-shore profile. The primary vertical axis in the figures corresponds to second and subsequent eigenfunctions while secondary vertical axis corresponds to the mean profile. The second eigenfunction reflects the presence of an upper beach ridge at Milford-on-Sea and inter-tidal beach trough and terrace at Narrabeen beach respectively, which distinctly deform the profiles from their mean profile shape. The third eigenfunction reflects the presence of a sub-tidal trough and a bar at both sites. The fourth eigenfunction implies sediment exchange across the profile, which reflects erosion of the upper beach at Milford-on-Sea and inter-tidal zone at Narrabeen Beach. The fifth eigenfunction and subsequent functions (not shown) may be related to other accumulative-erosive features in the profiles which contribute to deform the profile shape in time.
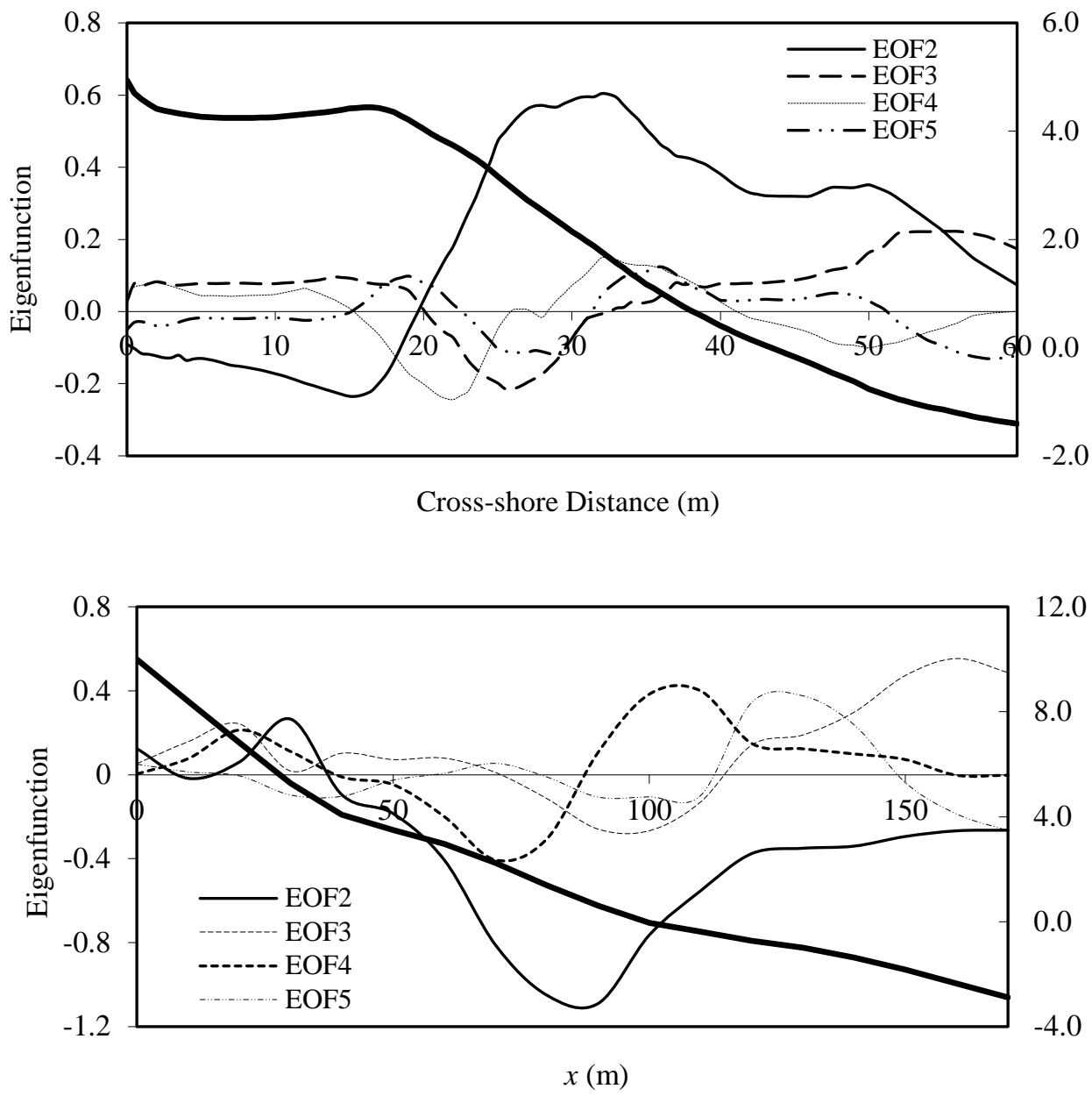

Figure 6. Spatial variation of first five Empirical Orthogonal Eigenfunctions. Milford-on-Sea (top) Narrabeen Beach (bottom).

There are distinct differences between the spatial eigenfunctions at Milford-on-Sea and Narrabeen Beach. At Milford-on-Sea, the spatial variability of all eigenfunctions is strongest between $18 \mathrm{~m}$ and 40 
m, which covers the entire swash zone and the upper part of the inter-tidal zone. This confirms that the sub-aerial (above MWL) beach undergoes the strongest morphodynamic variability, as indicated by the bulk statistical analysis of raw profile data. Eigenfunctions at the Narrabeen Beach show strongest variability beyond $60 \mathrm{~m}$, which covers the inter-tidal and sub-tidal zone of the profile. Variability of eigenfunctions in the swash region of the Narrabeen Beach is significantly smaller than that of the rest of the profile. On both beaches, spatial eigenfunctions do not reach constant values at the seaward end of the profile, indicating that the depth of closure is located further offshore from the truncation point of the measured profiles.

As seen in the third eigenfunction, the bar crest at Milford-on-Sea is located in the inter-tidal zone and therefore can be exposed at low tide. On the other hand, the bar crest on the Narrabeen profile is located in the sub-tidal zone and is submerged at all times except during low water spring tide. The fourth eigenfunction which implies sediment exchange cross the profile, shows offshore sediment transport, which typically happens during storms. At Milford-on-Sea, sediment moves from beach foreshore to the inter-tidal zone thus eroding the upper beach while at Narrabeen Beach, sediment moves from the inter-tidal zone to sub-tidal zone that lowers the sub-tidal beach. These characteristics show how each beach will respond to erosive events.

To investigate the temporal variability of different cross-shore morphological features at a range of time scales, temporal eigenfunctions were examined. The results are shown in Figure 7.
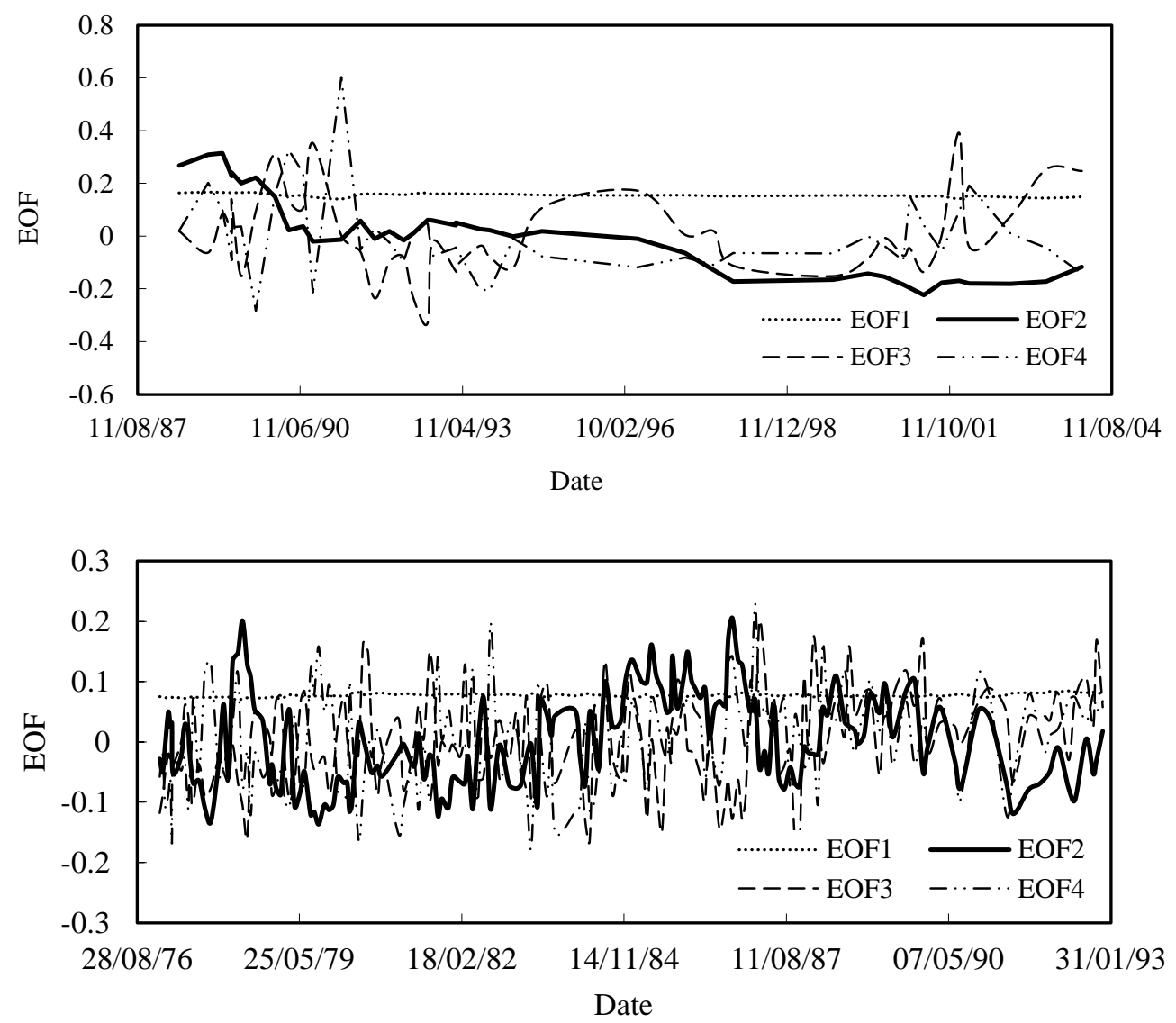

Figure 7 - Temporal variation of eigenfunctions. Milford-on-Sea Beach (top) and Narrabeen Beach (bottom)

The first temporal eigenfunction (EOF1) is approximately constant at both sites as it corresponds to the time-mean cross-shore beach profile. The second temporal eigenfunction (EOF2) at Milford-onSea exhibits a gradual decline over time, indicating long term beach recession due to degradation of the upper beach ridge. No seasonal signature is evident. EOF2 at Narrabeen Beach shows a high frequency signal with 3-5 month period as well as a longer-term 3-8 years cyclic variability. The high frequency variability can be attributed to frequent storms that govern the NSW wave climate. The lower frequency variability is likely to be due to the ENSO driven cyclic beach rotation signal at Narrabeen 
Beach as postulated by Ranasinghe et al., (2004). Although Profile 4, being approximately at the centre of the pocket beach, is thought to be least influenced by the rotation signal, the result in Figure 7 indicates that at least a small portion of the rotation signal may still be felt at this location, which is confirmed by the 3-8 year cyclic variability. The third eigenfunction (EOF3) at Milford-on-Sea shows a weak cyclical signal of period around 6 years and a clear seasonal signal. There is no evidence to interpret the 6-year cyclic variability at Milford-on-Sea. EOF3 at Narrabeen shows a seasonal signal only. All subsequent temporal eigenfunctions show either seasonal or high frequency signal which may corresponds to storm occurrence.

\section{CONCLUSIONS}

The paper investigates cross-shore morphodynamic evolution of a sand-gravel composite beach and compares that with a sandy beach. Long term historic beach profile surveys at Milford-on-Sea beach, UK (composite beach) and Narrabeen Beach, Australia (sand beach), were used and analysed using a variety of techniques to compare and contrast the behavioural characteristics of composite sand-gravel and sandy beaches at various time scales. Cross-shore profiles which are minimally affected by longshore transport processes are selected here as the focus is on cross-shore variability.

The time mean cross-shore profile at Milford-on-Sea beach indicates a reflective upper beach and a moderately dissipative lower beach. The sub-aqueous mean profile closely resembles Dean's equilibrium profile, with only 11\% RMSE, despite the complex of sediment mix and spatial variability of sediment characteristics. The observed differences can be attributed to the bimodal sediment distribution across the profile. This observation confirms that Dean's equilibrium profile can still be used as a suitable estimate of long-term profile evolution of a composite sand-gravel beach. The mean beach profile of the Narrabeen Beach is in close agreement with the Dean's equilibrium profile as expected, with only less than 5\% RMSE.

The standard deviation of profile depth shows that the swash zone is the most morphodynamically active region of the composite sand-gravel beach and the inter-tidal zone on the sandy beach. Both bulk statistical and EOF analyses confirm this observation and identifies cross-shore beach profile variability at different time scales. In the short-term, the composite sand-gravel beach responds to different wave conditions through variability in the upper beach (swash zone) while the sandy beach responds mainly through variability in the inter-tidal zone. This specific profile response characteristic may lead to distinctly different mechanisms of beach instability; a composite sand-gravel beach may become unstable due to sub-aerial profile cutback during storms while sandy beaches destabilise as a result of beach lowering. This same characteristic may make it more difficult for the upper foreshore of a composite sand-gravel beach to recover from an erosive event than for a sandy beach. Also, as Pontee et al (2004) observed, upper beach evolution is governed by the upper foreshore itself, and therefore recession of the foreshore contributes to further recession. This is supported by the form of the second eigenfunction which reflects the observation of steady recession of the beach foreshore at Milford-on-Sea and the mainly cyclical beach erosion at Narrabeen.

\section{ACKNOWLEDGEMENTS}

Beach profile surveys and wave data at Milford-on-Sea are from the Channel Coastal Observatory, UK. HK and DER acknowledge support from EPSRC through Grant EP/C005392/1 RF-PeBLE(“A Risk-based Framework for Predicting Long-term Beach Erosion”). JMH-C and DER acknowledge the support of the European Commission through FP7, 2009-1, Contract 244104 THESEUS ("Innovative technologies for safer European coasts in a changing climate”).

\section{REFERENCES}

Alegria-Arzaburu, A.R., Pedrozo-Acuna, A., Horrillo-Caraballo, J.M., Masselink, G. and Reeve, D.E., 2010. Determination of wave-shoreline dynamics of a macrotidal gravel beach using Canonical Correlation Analysis, Coastal Engineering, Vol. 57, 290-303.

Baldock, T. E., Holmes, P. and Horn, D.P., 1999. Low frequency swash motion induced by wave grouping, Coastal Engineering, 36, pp. 197-222.

Bradbury A.P. and Powell K.A., 1992. The short term profile response of shingle spits to storm wave action. Proc. 23rd International Conf. on Coastal Engineering, 2694-2707.

Brunn, P., 1954. Coast erosion and development of beach profiles, Technical Memorandum No. 44, beach Erosion Board. 
Carr, A.P., 1983. Shingle beaches: Aspects of their structure and stability. Shoreline Protection. Proceedings of Shore Protection, A conference organised by the Institution of Civil Engineers, University of Southampton, Thomas Telford, 69-76.

Carter, R.W.G. and Orford, J.D., 1984. Coarse clastic barrier beaches: a discussion of the distinctive dynamic and morphosedimentary characteristics, Marine Geology, Vol. 60, pp. 377-389.

Carter, J.D., 1986. Discussion: Gravel beach profile characterisation and discrimination, Journal of Coastal Research, Vol. 1(2), 129-139.

Carter, R.W.G. and Orford, J.D., 1993. The morphodynamics of coarse clastic barriers and beaches: a short and long term perspective, J. Coastal Res., Vol.15, 158-179.

Chadwick, A. J., Karunarathna, H., Gehrels, R, Massey, A. C.,O’Brien, D. ,Dales, D., 2005. A New Analysis of the Slapton Barrier Beach System. Maritime Engineering 158, 4, 147-161

Dean, R.G., 1977. Equilibrium beach profiles, US, Atlantic and Gulf Coasts, Department of Civil Engineering Ocean Engineering Report No. 12, University of Delaware, Delaware.

Dean, R.G., 1991. Equilibrium beach profiles: Characteristics and applications, Journal of Coastal Research, Vol. 7(1), 53-84.

Ivamy, M.C. and Kench, P.S., 2006. Hydrodynamic and morphological adjustment of a mixed sand and gravel beach, Torere, Bay of Plenty, New Zealand, Marine Geology, Vol. 228, 137-152.

Karunarathna, H., Chadwick, A.J. and Lawrence, J., 2005. Numerical Experiments of Swash Oscillations on Steep and Gentle Beaches, Coastal Engineering, Vol. 52, 497-511.

Kirk, R.M., 1980. Mixed sand and gravel beaches: Morphology, processes and sediments, Progress in Physical Geography, Vol.4, 189-210.

Kroon, A., Larson, M., Moller, I., Yokoki, H., Rozynski, G. Cox, J. and Larroude, P., 2008. Statistical analysis of coastal morphological data sets over seasonal to decadal time scales, Coastal Engineering, Vol. 55, 581-600.

Larson, M. and Kraus, N.C., 1994. Temporal and spatial scales of beach profile change, Duck, North Carolina, Marine Geology, Vol. 117, 75-94.

Larson, M., Capobianco, M., Jensen, H., Rozyanki, G., Southgate, H.N., Stive, M., Wijnberg, K.M. and Hulscher, S., 2003. Analysis and modelling of field data on coastal morphological evolution over yearly and decadal time scales, Part 1: Background and linear techniques, Journal of Coastal Research, Vol. 19(4), 760-775.

Martìn-Grandes, I., Hughes, J., Simmonds, D.J., Chadwick, A.J. \& Reeve, D.E., 2009. Novel methodology for one line model calibration using impoundment on mixed beach, Proc Coastal Dynamics 2009. DOI: $10.1142 / 9789814282475 \_0106$

Masselink, G. Russell, P., Blenkinsopp, C. and Turner, I., 2010. Swash zone sediment transport, step dynamics and morphological response on a gravel beach, Marine Geology, Vol. 274, 50-68.

McLean, R F and Kirk, R. M., 1969. Relationship between grain size, size-sorting, and foreshore slope on mixed sand- shingle beaches. New Zealand Journal Geology Geophysics, 12, 138-155.

Moore, B.D., 1982. Beach profile evolution in response to change in water level and wave height, Master's Thesis, Department of Civil Engineering, University of Delaware, pp.

Pilkey, O.H., Young, R.S., Riggs, S.R., Smith, A.W. and Pilkey, W.D., 1993. The concept of shore profile of equilibrium: A critical review, J. Coastal Research, Vol. 9(1), 255-278.

Pontee, N.I., Pye, K. and Blott, S.J., 2004. Morphodynamic behaviour and sedimentary variation of mixed sand and gravel beaches, Suffolk, UK, Journal of Coastal Research, Vol. 20(1), pp. 256-276.

Pruszak, Z., 1993. The analysis of beach profile changes using Dean's method and empirical orthogonal functions, Coastal Engineering, Vol. 19, 245-261.

Ranasinghe, R., McLoughlin, R., Short, A. and Symonds, G., 2004. The Southern Oscillation Index, wave climate and beach rotation, Marine Geology, Vol. 204, 273-287.

Reeve, D.E., Li, B. \& Thurston, N., 2001. "Eigenfunction analysis of decadal fluctuations in sandbank morphology at Great Yarmouth", Journal of Coastal Research, 17(2), 371-382.

Reeve, D.E., Horrillo-Caraballo, J.M. and Magar, V., 2008. Statistical Analysis and Forecasts of Longterm Sandbank Evolution at Great Yarmouth, UK, Estuarine, Coastal and Shelf Science, Vol. 79, 387-399.

Standing Conference on Problems Associated with the Coastline - SCOPAC, 2003. Sediment Transport Study. Hengistbury Head to Hurst Spit (http://www. Scopac .org.uk/scopac \%20sediment\% 20db/chrst/chrsttxt.pdf). [accessed March 2010].

Short, A. D. and Trenaman, N., 1992. Wave climate of the Sydney region, Aust. J. Mar. Freshw. Res., Vol. 42, 765-791. 
Short, A.D. and Wright, L.D., 1981. Beach systems of the Sydney region, Australian Geographer, Vol. $15,8-16$.

Short, A.D. and Trembanis, A.C., 2004. Decadal scale patterns in beach oscillation and rotation Narrabeen beach, Australia-Time series, PCA and Wavelet Analysis, Journal of Coastal Research, Vol. 20(2), 523-532.

Short, A.D., 1985. Rip current type, spacing and persistence, Narrabeen beach, Australia, Marine Geology, Vol. 65, pp. 47-71.

Sunamura, T. and Horikawa, K., 1974. Two dimensional beach transformation due to waves, Proc. $14^{\text {th }}$ Int. Conference in Coastal Engineering, 920-938.

Swart, D.H., 1974. A schematisation of onshore-offshore transport, Proc. $14^{\text {th }}$ Int. Conference in Coastal Engineering, 884-900.

Vellinga, P., 1983. Predictive computational model for beach and dune erosion during storm surges, Proc. Coastal Structures, ASCE, Washington D.C.

Vellinga, P., 1984. A tentative description of a universal erosion profile for sandy beaches and rock beaches. Coastal Engineering, Volume 8, Issue 2, 177-188.

Wijnberg, K.M. and Terwindt, J.H.J., 1995. Extracting decadal morphological behaviour from highresolution, long-term bathymetric surveys along the Holland coast using eigenfunction analysis, Marine Geology, Vol.126, 301-330.

Winant, C.D., Inman, D. and Nordstrom, C.E., 1975. Description of seasonal beach changes using Empirical Eigenfunctions, Journal of Geophysical Research, Vol. 80 (15), 1979-1986. 